\title{
Treadmill training with harness support: Selection of parameters for individuals with poststroke hemiparesis
}

\author{
George Chen, PhD; ${ }^{1-2}$ Carolynn Patten, PhD, PT ${ }^{1,3^{*}}$ \\ ${ }^{1}$ Rehabilitation Research and Development Center, Department of Veterans Affairs Palo Alto Health Care System, Palo \\ Alto, CA; ${ }^{2}$ Mechanical Engineering Department and ${ }^{3}$ Department of Orthopedic Surgery, Stanford University, Stanford, CA
}

\begin{abstract}
Locomotor training with a treadmill and harness support is a promising, task-oriented approach to restoring gait function in individuals with poststroke hemiparesis. However, a scientific basis for the proper selection of training parameters is lacking. Considerable latitude exists in the application of locomotor training, and training protocols vary widely between experimenters and clinical settings. Recent studies indicate that the prescription of certain parameters, including body-weight support (BWS) and treadmill speed, can affect treatment outcome in hemiparetic individuals. As an initial step toward developing a basis for selection of parameters, we reviewed the literature for studies that quantified the immediate (i.e., within session) biomechanical effects of adjusting BWS, treadmill speed, support stiffness, and handrail hold during treadmill walking in hemiparetic and nondisabled subjects. We then summarized results from personal investigations of these parameters. Based on the currently available evidence, we discuss the scientific rationale for selecting certain training parameters for individuals with poststroke hemiparesis and outline future directions for research.
\end{abstract}

Key words: biomechanics, body-weight support, cerebrovascular accident, gait, handrail hold, hemiparesis, rehabilitation, speed, support stiffness, treadmill.

\section{INTRODUCTION}

More than three-quarters of a million Americans suffer a first-ever stroke each year, and the survivor cohort now approaches three million persons [1]. Following stroke, many individuals are left with neurological and functional deficits, including hemiparesis, which impair their ability to walk. Approximately two-thirds of acute hospitalized stroke patients cannot walk independently at admission [2]. Of those who recover the ability to walk during acute rehabilitation, many are still handicapped by slow walking speed and limited endurance. These impairments restrict their independent mobility and autonomy and severely impact their quality of life.

Locomotor training with a treadmill and harness support is a promising, task-oriented approach to restoring gait function in individuals with poststroke hemiparesis [3-5]. During locomotor training, hemiparetic individuals exhibit a more symmetrical gait [6-8], with more normal kinematics and timing of muscle activity [7]. One or more therapists typically provide manual assistance to guide the trunk and legs through a normal gait trajectory. Improvements in functional locomotor ability, as reflected by increased ambulatory status or overground walking speed, have been demonstrated after locomotor training in individuals in both the subacute and chronic stages of hemiparesis [3-5,9-10]. However, no objective basis currently exists for the proper

Abbreviations: BWS = body-weight support, GRF = ground reaction force, $\mathrm{KE}=$ kinetic energy.

* Address all correspondence to Carolynn Patten, PhD; Rehabilitation Research and Development Center/153, VA Palo Alto Health Care System, 3801 Miranda Ave, Palo Alto, CA 94304-1200; 650-493-5000, ext 63593; fax: 650493-4919. Email: patten@rrd.stanford.edu

DOI: 10.1682/JRRD.2005.04.0063 
selection of locomotor training parameters for hemiparetic persons following stroke.

Considerable variability exists in the current application of poststroke locomotor training. This variability, along with emerging evidence that the selection of training parameters can affect treatment outcomes [4-5,10], strongly indicates that a scientific basis for the proper selection of locomotor training parameters is overdue. Ultimately, we need to address the entire ensemble of factors that can affect the locomotor training paradigm, including immediate biomechanical effects, key elements of the perceptual environment, cognition, and physiological adaptations to training intensity and duration (heart and respiratory rate, etc.).

In this focused review, we summarize the current approaches taken by experimenters in prescribing locomotor training parameters for persons with poststroke hemiparesis. Next, as an initial step toward developing a scientific basis for parameter selection, we reviewed the literature for studies that quantified the immediate (i.e., within session) biomechanical effects of adjusting bodyweight support (BWS), speed, support stiffness, and handrail hold during treadmill walking in both hemiparetic and nondisabled subjects. We then follow with results from personal investigations of these parameters. Finally, based on the currently available evidence, we discuss the scientific rationale for selecting certain training parameters for individuals with poststroke hemiparesis and outline future directions for research.

\section{CURRENT APPROACHES IN PRESCRIBING LOCOMOTOR TRAINING PARAMETERS}

Investigators have taken various approaches in the prescription of BWS during locomotor training in hemiparetic individuals (Table 1). Based on clinical experience, many investigators prescribed an initial level of 30 to 40 percent BWS and reduced this level as subjects improved their ability to bear weight on the paretic limb [3-4,11-12]. Visintin et al. selected the initial level of support by observing subjects while they walked at 10 , 20,30 , and 40 percent BWS and selecting the percentage that facilitated proper trunk and limb alignment [5]. Some investigators trained hemiparetic subjects without BWS $[9,13]$ or provided support only during the first few sessions [10].

As is the case with BWS, considerable variability exists in the prescription of treadmill speed during train- ing (Table 1). Hesse et al. deliberately limited treadmill speed to permit longer training sessions and facilitate manual gait corrections [3]. Similarly, Werner et al. set slow target velocities to avoid overexertion [14]. Other investigators challenged subjects with faster treadmill speeds and increased these speeds as subjects' walking abilities improved [5,10-13,15]. Da Cunha et al. increased treadmill speed when a specified step length could be taken at a higher speed [11], while Pohl et al. increased speed when subjects could walk $10 \mathrm{~s}$ without stumbling at the slower speed [10]. Alternatively, Silver et al. advanced speed such that subjects trained at 60 to 70 percent of their maximum heart rate reserve [13].

Moreover, studies of locomotor training in persons with poststroke hemiparesis have varied in their method of BWS, use of handrail hold, application of manual assistance, and frequency and duration of training sessions (Table 1). Some researchers used more compliant BWS systems, which permitted modest trunk motion during walking and maintained a stable support force [3-4,15]. Others used stiffer systems, which constrained trunk motion and unweighted subjects by lifting them higher relative to the treadmill surface $[5,12]$. Most researchers provided subjects with a handrail hold during training [4-5, 9,12-13,15] and manual assistance by one or two therapists as needed [3-5,12,14-15]. However, the relative importance of these two parameters is not well understood. Training duration has been highly variable, ranging from 3 to 9 weeks; session length and frequency have ranged from 4 to 45 minutes a day, 3 to 5 days a week [3-5,9-15].

\section{EVIDENCE THAT LOCOMOTOR TRAINING PARAMETERS AFFECT TREATMENT OUTCOME}

Recent studies indicate that the prescription of certain parameters, specifically BWS and treadmill speed, can affect treatment outcome in hemiparetic individuals [4-5,10]. Visintin et al. studied 100 hemiparetic subjects and found locomotor training with BWS to be more effective than training without support for motor recovery measures (i.e., lower-limb portion of the Stroke Rehabilitation Assessment of Movement [16]), functional balance (i.e., Balance Scale [17]), overground walking speed, and walking endurance [5]. Pohl et al. [10] and Sullivan et al. [4] found locomotor training to be more effective for groups that trained at faster speeds. Both studies examined overground walking speed as the outcome measure $[4,10]$. Pohl et al. also examined cadence, stride length, and 
Table 1.

Parameter selection for locomotor treadmill training of persons with poststroke hemiparesis.

\begin{tabular}{|c|c|c|c|c|c|c|}
\hline Citation & Population & BWS & Treadmill Speed & $\begin{array}{l}\text { Support System } \\
\text { Stiffness }\end{array}$ & Handrail Hold & $\begin{array}{l}\text { Other Training } \\
\text { Parameters }\end{array}$ \\
\hline Laufer et al., 2001 [4] & $\begin{array}{l}n=25 \\
<3 \text { mo } \\
\text { post-CVA. }\end{array}$ & Not reported. & $\begin{array}{l}\text { Adjusted to subject's } \\
\text { CWS. }\end{array}$ & Not applicable. & $\begin{array}{l}\text { Generally, subjects } \\
\text { held a horizontal bar } \\
\text { at their front or side } \\
\text { during training. }\end{array}$ & $\begin{array}{l}\text { Trained for } 15 \text { ses- } \\
\text { sions, } 5 \mathrm{~d} / \mathrm{wk} \text {; first } \\
\text { week: } 4 \mathrm{~min} / \mathrm{d} \text {; second } \\
\text { week: } 6 \mathrm{~min} / \mathrm{d} \text {; third } \\
\text { week: } 8 \mathrm{~min} / \mathrm{d} \text {. }\end{array}$ \\
\hline Nilsson et al., 2001 [5] & $\begin{array}{l}n=73 \text {; } \\
<8 \text { wk post- } \\
\text { CVA, } \\
<0.71 \mathrm{~m} / \mathrm{s} \\
\text { walking } \\
\text { speed. }\end{array}$ & $\begin{array}{l}\text { Individual; adjusted } \\
\text { as walking ability } \\
\text { improved. }\end{array}$ & $\begin{array}{l}\text { Individual; adjusted as } \\
\text { walking ability } \\
\text { improved. }\end{array}$ & $\begin{array}{l}\text { TR Spacetrainer } \\
\text { Stiffness appeared } \\
\text { low: "BWS kept } \\
\text { constant throughout } \\
\text { gait cycle by follow- } \\
\text { ing vertical displace- } \\
\text { ment of body.” }\end{array}$ & $\begin{array}{l}\text { Subjects allowed to } \\
\text { take balance support } \\
\text { on a crossbar. }\end{array}$ & $\begin{array}{l}\text { Trained for } \sim 2 \text { mo, } \\
30 \text { min/d, } 5 \text { d/wk. Few } \\
\text { subjects manually } \\
\text { assisted by } \\
2 \text { therapists. }\end{array}$ \\
\hline Silver et al., 2000 [7] & $\begin{array}{l}n=5 \\
>6 \text { mo } \\
\text { post-CVA. }\end{array}$ & Not reported. & $\begin{array}{l}\text { Individual; adjusted } \\
\text { such that subject } \\
\text { trained at } 60 \%-70 \% \text { of } \\
\text { maximum heart rate } \\
\text { reserve. }\end{array}$ & Not applicable. & $\begin{array}{l}\text { Permitted handrail } \\
\text { support ad lib. }\end{array}$ & $\begin{array}{l}\text { Trained for } 3 \mathrm{mo} \text {, up } \\
\text { to } 40 \mathrm{~min} / \mathrm{d}, 3 \mathrm{~d} / \mathrm{wk} \text {. }\end{array}$ \\
\hline $\begin{array}{l}\text { Sullivan et al., } 2002 \\
\text { [8] }\end{array}$ & $\begin{array}{l}n=24 ; \\
>6 \text { mo post- } \\
\text { CVA, walk- } \\
\text { ing speeds at } \\
\text { least } 50 \% \\
\text { below }\end{array}$ & $\begin{array}{l}\text { Initially up to } 40 \% \text {; } \\
\text { decreased as activity } \\
\text { tolerance increased } \\
\text { and proper kinemat- } \\
\text { ics could be main- } \\
\text { tained during stance/ }\end{array}$ & $\begin{array}{l}\text { Slow: } 0.22 \mathrm{~m} / \mathrm{s} \text {; Vari- } \\
\text { able: } 0.22,0.45,0.67 \text {, } \\
\text { and } 0.89 \mathrm{~m} / \mathrm{s} \text {; Fast: } \\
0.89 \mathrm{~m} / \mathrm{s} \text {. }\end{array}$ & $\begin{array}{l}\text { Overhead-motorized } \\
\text { pneumatic lift. }^{\S}\end{array}$ & $\begin{array}{l}\text { Subjects positioned } \\
\text { within parallel bars; } \\
\text { discouraged from } \\
\text { using them for sup- } \\
\text { port, except at study } \\
\text { onset. }\end{array}$ & $\begin{array}{l}\text { Trained } 12 \text { sessions } \\
\text { over } 4-5 \text { wk, } 20 \text { min/ } \\
\text { session. Manually } \\
\text { assisted by } 1 \text { therapist } \\
\text { and } 1 \text { aide. }\end{array}$ \\
\hline
\end{tabular}


JRRD, Volume 43, Number 4, 2006

Table 1. (Continued)

Parameter selection for locomotor treadmill training of persons with poststroke hemiparesis.

\begin{tabular}{|c|c|c|c|c|c|c|}
\hline Citation & Population & BWS & Treadmill Speed & $\begin{array}{l}\text { Support System } \\
\text { Stiffness }\end{array}$ & Handrail Hold & $\begin{array}{c}\text { Other Training } \\
\text { Parameters }\end{array}$ \\
\hline Visintin et al., 1998 [9] & $\begin{array}{l}n=100 \\
<6 \text { mo } \\
\text { post-CVA. }\end{array}$ & $\begin{array}{l}\text { Experimental: up to } \\
40 \% \text { initially; pro- } \\
\text { gressively decreased. } \\
\text { Control: Not provided. }\end{array}$ & $\begin{array}{l}\text { Increased as subject's } \\
\text { walking ability } \\
\text { improved. }\end{array}$ & Not reported." & $\begin{array}{l}\text { Subjects could hold } \\
\text { on to horizontal bar at } \\
\text { front of treadmill for } \\
\text { stability. }\end{array}$ & $\begin{array}{l}\text { Trained for } 6 \text { wk, } \\
20 \text { min/d, } 4 \text { d/wk. } \\
\text { Manually assisted by } \\
1 \text { or } 2 \text { therapists as } \\
\text { needed. }\end{array}$ \\
\hline $\begin{array}{l}\text { Werner et al., } 2002 \\
\text { [10] }\end{array}$ & $\begin{array}{l}n=30 ; \text { non- } \\
\text { ambulatory, } \\
\text { 4-12 wk } \\
\text { post-CVA. }\end{array}$ & $\begin{array}{l}\text { Partially supported } \\
\text { and reduced as sub- } \\
\text { jects could take their } \\
\text { full weight. }\end{array}$ & $\begin{array}{l}\text { Relatively slow ( } 0.25- \\
0.40 \mathrm{~m} / \mathrm{s} \text { ) to avoid over- } \\
\text { exertion of subjects. }\end{array}$ & Not reported. & $\begin{array}{l}\text { Figure showed sub- } \\
\text { ject holding on to bar } \\
\text { in front of treadmill. }\end{array}$ & $\begin{array}{l}\text { Trained for } 3 \mathrm{wk} \text {, } \\
\text { 15-20 } \mathrm{min} / \mathrm{d}, 5 \mathrm{~d} / \mathrm{wk} \text {. } \\
\text { Manually assisted as } \\
\text { needed. }\end{array}$ \\
\hline
\end{tabular}

1. Da Cunha IT Jr, Lim PA, Qureshy H, Henson H, Monga T, Protas EJ. Gait outcomes after acute stroke rehabilitation with supported treadmill ambulation training: A randomized controlled pilot study. Arch Phys Med Rehabil. 2002;83(9):1258-65. [PMID: 12235606]

2. Hesse S, Bertelt C, Jahnke MT, Schaffrin A, Baake P, Malezic M, Mauritz KH. Treadmill training with partial body-weight support compared with physiotherapy in nonambulatory hemiparetic patients. Stroke. 1995;26(6):976-81. [PMID: 7762049]

3. Kosak MC, Reding MJ. Comparison of partial body weight-supported treadmill gait training versus aggressive bracing assisted walking post stroke. Neurorehabil Neural Repair. 2000;14(1):13-19. [PMID: 11228945]

4. Laufer Y, Dickstein R, Chefez Y, Marcovitz E. The effect of treadmill training on the ambulation of stroke survivors in the early stages of rehabilitation: A randomized study. J Rehabil Res Dev. 2001;38(1):69-78. [PMID: 11322472]

5. Nilsson L, Carlsson J, Danielsson A, Fugl-Meyer A, Hellstrom K, Kristensen L, Sjolund B, Sunnerhagen KS, Grimby G. Walking training of patients with hemiparesis at an early stage after stroke: A comparison of walking training on a treadmill with body-weight support and walking training on the ground. Clin Rehabil. 2001;15(5):515-27. [PMID: 11594641]

6. Pohl M, Mehrholz J, Ritschel C, Ruckriem S. Speed-dependent treadmill training in ambulatory hemiparetic stroke patients: A randomized controlled trial. Stroke. 2002;33(2):553-58. [PMID: 11823669]

7. Silver KH, Macko RF, Forrester LW, Goldberg AP, Smith GV. Effects of aerobic treadmill training on gait velocity, cadence, and gait symmetry in chronic hemiparetic stroke: A preliminary report. Neurorehabil Neural Repair. 2000;14(1):65-71. [PMID: 11228951]

8. Sullivan KJ, Knowlton BJ, Dobkin BH. Step training with body-weight support: Effect of treadmill speed and practice paradigms on poststroke locomotor recovery. Arch Phys Med Rehabil. 2002;83(5):683-91. [PMID: 11994808]

9. Visintin M, Barbeau H, Korner-Bitensky N, Mayo NE. A new approach to retrain gait in stroke patients through body-weight support and treadmill stimulation. Stroke. 1998;29(6):1122-28. [PMID: 9626282]

10. Werner C, Von Frankenberg S, Treig T, Konrad M, Hesse S. Treadmill training with partial body-weight support and an electromechanical gait trainer for restoration of gait in subacute stroke patients: A randomized crossover study. Stroke. 2002;33(12):2895-2901. [PMID: 12468788]

*System likely compliant (Source: Hesse S, Helm B, Krajnik J, Gregoric M, Mauritz KH. Treadmill training with partial body-weight support: Influence of body weight release on the gait of hemiparetic patients. J Neurol Rehabil. 1997;11(1):15-20, and Hesse S, Konrad M, Uhlenbrock D. Treadmill walking with partial body-weight support versus floor walking in hemiparetic subjects. Arch Phys Med Rehabil. 1999;80(4):421-27. [PMID: 10206604]

${ }^{\dagger}$ Columbus McKinnon Corp, Amherst, New York.

${ }^{\ddagger}$ TR Equipment AB, Tranas, Sweden.

${ }^{\S}$ Vigor Equipment, Inc., Stevensville, Michigan; System compliant (personal observation at University of California Los Angeles locomotion laboratory).

"Support system fairly rigid (Source: Barbeau H, Wainberg M, Finch L. Description and application of a system for locomotor rehabilitation. Med Biol Eng Comput. 1987;25(3):341-44. [PMID: 3449731]).

BWS = body-weight support, CVA = cerebrovascular accident, CWS = comfortable walking speed, LTT = limited progressive treadmill training, STAT = supported treadmill ambulation training, STT $=$ speed-dependent treadmill training.

Functional Ambulation Category [10]. Taken together, this emerging evidence that the selection of training parameters can affect treatment outcome [4-5,10] motivates investigation of a scientific basis for the proper selection of locomotor training parameters.

\section{BIOMECHANICAL EFFECTS OF TRAINING PARAMETER ADJUSTMENT}

As an initial step toward developing a scientific basis for selection of locomotor training parameters, we focus the remainder of this review on the body of literature that quantified the immediate (i.e., within session) biomechanical effects of adjusting BWS, speed, support stiffness, and handrail hold during treadmill walking in hemiparetic and nondisabled subjects.

\section{Treadmill Versus Overground Walking}

Even without harness support, hemiparetic persons have a more symmetrical gait during treadmill walking than during overground walking [7-8,18] (Table 2). Most notably, paretic single-limb support time is increased (by 7.5\% [7] to $11.2 \%$ [18]). This increase in single-limb support time may be an important aspect of the training paradigm, since it more greatly challenges subjects' equilibrium reflexes and ability to tolerate and 
Table 2.

Biomechanical effects of training parameter adjustment.

\begin{tabular}{|c|c|c|c|c|c|c|c|}
\hline Citation & Population & $\begin{array}{l}\text { Treadmill vs } \\
\text { Overground }\end{array}$ & BWS & Treadmill Speed & $\begin{array}{l}\text { Support System } \\
\text { Stiffness }\end{array}$ & Handrail Hold & Notes \\
\hline $\begin{array}{l}\text { Bayat et al., } \\
2005 \text { [1] }\end{array}$ & $\begin{array}{l}n=10 ; \\
\text { mean } 9.1 \mathrm{wk} \\
\text { post-CVA; } \\
5 \text { nondisabled. }\end{array}$ & $\begin{array}{l}\text { On treadmill, subjects } \\
\text { exhibited slower CS, } \\
\text { MS, shorter SL, higher } \\
\text { cadences relative to } \\
\text { overground. }\end{array}$ & Not provided. & $\begin{array}{l}\text { On treadmill, at MS, } \\
\text { subjects exhibited } \\
\text { higher cadence } \\
\text { (+22\%), longer SL } \\
\text { (+26\%) relative to CS. }\end{array}$ & Not applicable. & Not provided. & - \\
\hline $\begin{array}{l}\text { Finch et al., } \\
1991 \text { [2] }\end{array}$ & $\begin{array}{l}n=10 \\
\text { nondisabled. }\end{array}$ & Not examined. & $\begin{array}{l}\text { With increased BWS } \\
\text { (0\%-70\%), \% stance, } \\
\text { hip-knee angular } \\
\text { displacement, antigravity } \\
\text { muscle activity } \\
\text { decreased, single-limb } \\
\text { support time increased } \\
\text { 25\%. }\end{array}$ & Not examined. & Not examined. & Not examined. & - \\
\hline $\begin{array}{l}\text { Gordon } \\
\text { et al., } \\
2000 \text { [3] }\end{array}$ & $\begin{array}{l}n=2, \\
\text { nondisabled. }\end{array}$ & Not examined. & Not examined. & Not examined. & $\begin{array}{l}\text { Stiff, position- } \\
\text { controlled system } \\
\text { restricted vertical pel- } \\
\text { vis movement and } \\
\text { reduced peaks in } \\
\text { GRF during heel } \\
\text { strike and toe-off. } 2 \\
\text { compliant, force- } \\
\text { controlled systems } \\
\text { (open- and closed- } \\
\text { loop) allowed verti- } \\
\text { cal COM movement }\end{array}$ & Not examined. & $\begin{array}{l}\text { In open- } \\
\text { loop force- } \\
\text { controlled } \\
\text { system, fluc- } \\
\text { tuations in } \\
\text { harness forces } \\
\text { may have } \\
\text { affected peaks } \\
\text { in GRF during } \\
\text { heel strike and } \\
\text { toe-off. }\end{array}$ \\
\hline
\end{tabular}

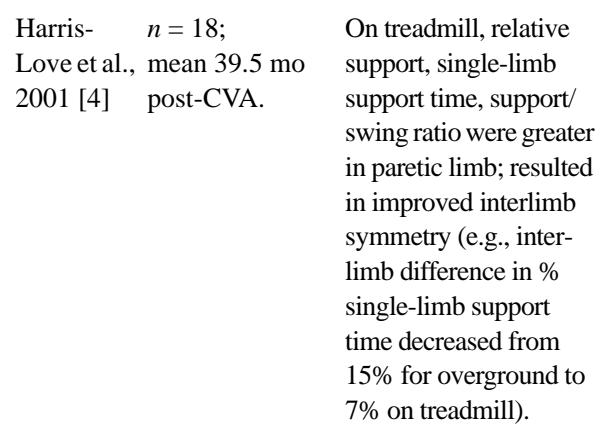

\section{On treadmill, relative support, single-limb support time, support/ swing ratio were greater in paretic limb; resulted in improved interlimb symmetry (e.g., inter- limb difference in \% single-limb support time decreased from $15 \%$ for overground to $7 \%$ on treadmill).}

3 of 7 subjects had greater symmetry in single-limb support

Within $0 \%-50 \%$ BWS, single-limb support time ratio improved time for treadmill at $0 \%$ most consistently at BWS (interlimb sup- $15 \%$ and 30\% BWS port time ratio $=0.94)$ Single-limb load ratio than for overground worsened with walking (ratio $=0.74)$. increased BWS.

Not examined.

.

\section{With increased BWS Not examined.} (0\%-60\%), relative double support time, vastus and soleus activity, and hip/knee flexion decreased. Relative single-limb support time increased (from $45 \%$ to $76 \%$ total stance time).

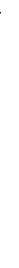

Not examined. Speeds matched between overground and treadmill walking.

Did not affect symmetry. similar to overground.

$$
\begin{array}{ll}
\begin{array}{l}
\text { Not examined; } \\
\text { subjects allowed to }
\end{array} & \text { Effect of } \\
\text { use handrails for } & \text { for treadmill hold } \\
\text { postural stability. } & \text { walking not } \\
& \text { accounted for. }
\end{array}
$$

\author{
Not examined; $\quad$ Not examined; $\quad$ Data set defi- \\ harness attached to subjects rested cient; small \\ motorized lift. ${ }^{\dagger} \quad$ hands on side rails sample size; \\ to reduce lateral some subjects \\ sway. \\ could not \\ complete all \\ trials.
}

$\begin{array}{lll}\text { Not examined. BWS } & \text { Not examined; sub- } & \text { Differences in } \\ \text { support system } & \text { jects provided hand- } & \text { kinematics } \\ \text { appeared compliant } & \text { rail hold when } & \text { assessed qual- } \\ \text { from following state- } & \text { necessary. } & \text { itatively by } \\ \text { ment: "The system } & \text { raters using } \\ \text { provided a preset } & \text { videotaped } \\ \text { degree of BWS con- } & \text { trials. In } 4 \\ \text { trolled by force } & \text { subjects, } \\ \text { transducers located } & \text { paretic limb } \\ \text { between the harness } & \text { swing assisted } \\ \text { and pulleys.” } & \text { by therapist. }\end{array}$


Table 2. (Continued)

Biomechanical effects of training parameter adjustment.

\begin{tabular}{|c|c|c|c|c|c|c|c|}
\hline Citation & Population & $\begin{array}{l}\text { Treadmill vs } \\
\text { Overground }\end{array}$ & BWS & Treadmill Speed & $\begin{array}{c}\text { Support System } \\
\text { Stiffness }\end{array}$ & Handrail Hold & Notes \\
\hline
\end{tabular}

1. Bayat R, Barbeau H, Lamontagne A. Speed and temporal-distance adaptations during treadmill and overground walking following stroke. Neurorehabil Neural Repair. 2005;19(2):115-24. [PMID: 15883355]

2. Finch L, Barbeau H, Arsenault B. Influence of body-weight support on normal human gait: Development of a gait retraining strategy. Phys Ther. 1991;71(11):842-55, discussion 855-56. [PMID: 1946621]

3. Gordon KE, Ferris DP, Beres JA, Roberton M, Harkema SJ. The importance of using an appropriate body-weight support system in locomotor training. Soc Neurosci. 2000;26(1):160.

4. Harris-Love ML, Forrester LW, Macko RF, Silver KH, Smith GV. Hemiparetic gait parameters in overground versus treadmill walking. Neurorehabil Neural Repair. 2001;15(2):105-12. [PMID: 11811252]

5. Hassid E, Rose D, Commisarow J, Guttry M, Dobkin BH. Improved gait symmetry in hemiparetic stroke patients induced during body weight-supported treadmill stepping. J Neurol Rehabil. 1997;11(1):21-26.

6. Hesse S, Helm B, Krajnik J, Gregoric M, Mauritz KH. Treadmill training with partial body-weight support: Influence of body weight release on the gait of hemiparetic patients. J Neurol Rehabil. 1997;11(1):15-20.

7. Hesse S, Konrad M, Uhlenbrock D. Treadmill walking with partial body-weight support versus floor walking in hemiparetic subjects. Arch Phys Med Rehabil. 1999;80(4):421-27. [PMID: 10206604]

8. Hesse S, Werner C, Paul T, Bardeleben A, Chaler J. Influence of walking speed on lower limb muscle activity and energy consumption during treadmill walking of hemiparetic patients. Arch Phys Med Rehabil. 2001;82(11):1547-50. [PMID: 11689974]

*Support system fairly rigid (Source: Barbeau H, Wainberg M, Finch L. Description and application of a system for locomotor rehabilitation. Med Biol Eng Comput. 1987;25(3):341-44. [PMID: 3449731])

${ }^{\dagger}$ System was rigid; personal observation at University of California Los Angeles locomotion laboratory.

${ }^{\ddagger}$ Personal correspondence with Hesse.

BWS = body-weight support, COM = center of mass, CS = comfortable speed, CVA = cerebrovascular accident, GRF $=$ ground reaction force, $\mathrm{HR}=$ heart rate, MS = maximum speed, SL = stride length, v SAS = self-adopted speed.

control weight-bearing on the paretic limb [7-8,18-19]. In a study where hemiparetic subjects were not provided a handrail hold during treadmill walking, Bayat et al. observed that both comfortable and maximum walking speeds on the treadmill were significantly lower than during overground walking [20]. The importance of handrail hold to locomotor training, especially when harness support is not provided, remains poorly understood.

\section{Effect of Body-Weight Support}

The level of BWS during treadmill walking has been observed to affect gait kinematics and temporal-distance 
measures in hemiparetic [6-8] and nondisabled subjects [21] (Table 2). In hemiparetic subjects, Hesse et al. observed that single-limb support time for the paretic limb, and to a lesser extent for the nonparetic limb, increased (from $45 \%-76 \%$ of total stance time [6]) as a function of increased BWS, which resulted in improved symmetry in single-limb support time [6-7]. Hassid et al. observed that symmetry in single-limb support time appeared to improve most consistently at 15 to 30 percent BWS [8]. However, because of the small sample size of the study, the latter results were not statistically significant [8].

With increased BWS, Hesse et al. also observed more upright walking postures in hemiparetic subjects, including increased hip and knee extension during stance [6]. At support up to 45 percent of body weight, joint angular displacement profiles improved toward normal and were accompanied by an increase in plantigrade weight acceptance [6]. However, when BWS reached 60 percent, subjects tended to walk on their toes, particularly with their nonparetic limb [6]. Also, hip and knee flexion during swing and activity of the antigravity muscles during stance decreased at higher levels of BWS [6]. As a result, these investigators advised against BWS levels greater than 30 percent [6].

\section{Effect of Treadmill Speed}

The immediate gait response to changes in treadmill speed in hemiparetic subjects has been studied by multiple investigators $[8,22]$. In a small sample of subjects, Hassid et al. observed that moderate increases in treadmill speed did not affect symmetry in either weight supported by or time spent on each limb during single-limb support [8]. Thus, they proposed the appropriateness of faster treadmill speeds, within the subjects' capabilities, to train subjects to independently walk overground at maximum possible speeds [8]. Hesse et al. observed cadence ( $r=0.75)$, stride length $(r=0.78)$, heart rate $(r=$ 0.54 ), and mean muscular activities of the lower-limb muscles (tibialis anterior, $r=0.12$; gastrocnemius, $r=$ 0.37; vastus lateralis, $r=0.19$; rectus femoris, $r=0.31$; and biceps femoris, $r=0.45$ ) to correlate positively with treadmill speed [22]. Moreover, energy $(r=-0.67)$ and cardiac costs $(r=-0.55)$ were observed to correlate negatively with speed, which indicated improved metabolic efficiency at faster speeds [22]. Thus, these investigators concluded that hemiparetic subjects should be challenged to walk fast on the treadmill to activate the relevant weight-bearing muscles and improve locomotor efficiency [22].

\section{Effect of Support System and Stiffness}

Gordon et al. observed that the characteristics of the BWS system can affect vertical movement of the pelvis and ground reaction forces (GRF) during treadmill walking (Table 2) [23]. The subjects, two nondisabled individuals and two persons with spinal cord injury, walked at a range of speeds $(0.54-1.34 \mathrm{~m} / \mathrm{s})$ while BWS was provided by either a rigid cable or a compliant pneumatic cylinder [23]. Because the subjects with spinal cord injury could not walk independently on the treadmill, they were provided with manual assistance [23]. The rigid support was observed to restrict vertical pelvic movement and reduce peaks in the vertical GRF at heel strike and toe-off [23]. In contrast, the compliant pneumatic support allowed vertical pelvic movement similar to that observed in overground locomotion [23]. However, peaks in vertical GRF at heel strike were exaggerated relative to those observed at toe-off [23]. Since support forces still fluctuated with trunk motion, the abnormal vertical GRF profile may have been due to viscosity in the pneumatic system, [23]. Indeed, when one of the nondisabled subjects repeated the experiment while supported by the pneumatic cylinder with additional force regulation, vertical GRFs were observed to be more comparable with those observed during overground locomotion adjusted for BWS [23]. On the basis of these observations, the investigators concluded that the characteristics of the BWS system used during locomotor training affect both vertical center of mass movement and GRF profiles. These variables influence motor output, since they reflect the loading experienced during training, which is known to modulate proprioceptive influences during locomotion [23].

\section{Effect of Handrail Hold}

The specific effect of handrail hold during treadmill walking has not been examined. However, the majority of the reviewed studies on persons with poststroke hemiparesis (Table 2) provided a handrail hold to subjects [6-8,18,22]. Most notably, the three studies that compared the gait of hemiparetic subjects during overground and treadmill walking without harness support $[7-8,18]$ provided subjects a handrail hold during treadmill walking. In these studies, gait symmetry and single-limb support time in the paretic limb were greater during treadmill walking. 
However, whether these reported differences were related to mechanical/perceptual differences between treadmill and overground walking or the addition of handrail hold during treadmill walking is unclear.

\section{Effects of Training Parameter Adjustment}

We conducted a pilot study to systematically test the biomechanical effects of adjusting BWS, speed, support stiffness, and handrail hold during treadmill walking in hemiparetic subjects. Detailed methodology and results were presented in Chen et al. and are summarized here [24]. Three-dimensional bilateral kinematic and insole pressure data were collected while hemiparetic subjects walked on a treadmill with different combinations of locomotor training parameters. We examined the effects of support stiffness using a custom-designed support frame [25], which allowed stiffness to be adjusted in known increments with minimal frictional and viscous contributions to the support force. The effects of handrail hold were isolated by having subjects walk with and without handrail hold during treadmill walking with and without harness support. By comparing gait characteristics of hemiparetic and nondisabled subjects at matched treadmill speeds, we identified gait deviations consistently associated with hemiparesis independent of the slow walking speeds typically observed in hemiparetic subjects [26]. Changes in these gait deviations were subsequently assessed during treadmill walking as training parameters were systematically adjusted [24].

Specific gait deviations associated with hemiparesis were normalized during treadmill walking with increased BWS, treadmill speed, and support stiffness and the addition of handrail hold. In the hemiparetic subjects, leg kinetic energy (KE) at toe-off in the nonparetic limb was exaggerated relative to side-matched limbs in nondisabled control subjects (Figure 1(a), dashed vs solid line), which resulted in reduced swing time in the nonparetic limb (Figure 1(b), dashed vs solid line) consistent with weakness or poor balance during single-limb support on the paretic limb [26]. With increased BWS (from 0\% - 50\%), the exaggerated leg $\mathrm{KE}$ at toe-off in the nonparetic limb was reduced $(-37 \%)$ and nonparetic limb swing time increased (+52\%) (Figure 1(a)-(b)), which resulted in increased single-limb support time on the paretic limb [24].

In the hemiparetic subjects, leg $\mathrm{KE}$ at toe-off in the paretic limb was reduced relative to nondisabled control subjects (Figure 1(c), dashed vs solid line), a finding consistent with inadequate leg propulsion by the plantar
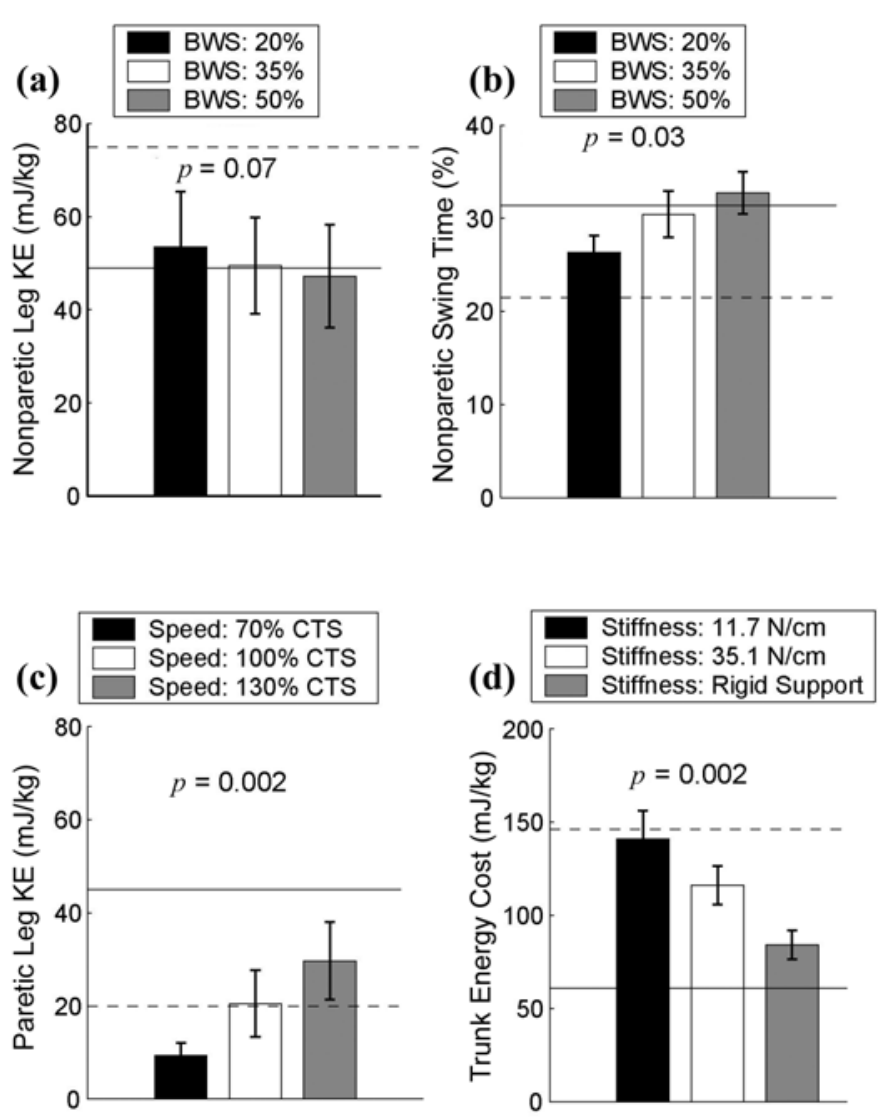

Figure 1.

Differences between (a) leg kinetic energy (KE) at toe-off and (b) swing time for nonparetic limb at different levels of body-weight support (BWS). Differences between (c) leg KE at toe-off for paretic limb at different treadmill speeds and (d) energy costs associated with raising trunk during preswing and swing of paretic limb at different support stiffnesses. Error bars represent standard error of mean. Dashed and solid lines represent, respectively, mean for hemiparetic and nondisabled control subjects during unsupported treadmill walking. CTS = comfortable treadmill speed. Source: Chen G, Patten C, Kothari DH, Zajac FE. Gait deviations associated with post-stroke hemiparesis: Improvement during treadmill walking using weight support, speed, support stiffness, and handrail hold. Gait Posture. 2005;22(1):57-62. [PMID: 15996593]

flexors [26]. Inadequate paretic limb propulsion during preswing may limit how fast the limb is able to advance during swing, with consequent effects on gait speed. With increased treadmill speed (from $70 \%-130 \%$ of the subject's comfortable speed), leg KE at toe-off in the paretic limb was increased (+230\%) (Figure 1(c)) [24]. Increased leg KE elicited by training at faster treadmill speeds could be important, both for achieving faster 
overground walking speeds and for improving swing initiation and knee flexion at slower speeds.

In the hemiparetic subjects, the energy cost associated with raising the trunk during preswing and swing of the paretic limb was exaggerated (Figure 1(d), dashed vs solid line) [26]. This finding is consistent with pelvic hiking for compensation of reduced knee flexion during swing in the paretic limb. With increased support stiffness (from $11.7 \mathrm{~N} / \mathrm{cm}$ to a rigid support), the exaggerated energy cost associated with raising the trunk was reduced $(-40 \%)$ (Figure 1(d)) [24]. Restoration of normal displacements of the trunk has been stressed in locomotor training, because it strongly affects the sensory experience that is believed to be critical for achieving optimal training results $[23,27]$. Moreover, exaggerated displacements of the trunk during walking in hemiparetic individuals contribute to increased mechanical energetic cost [28].

Similar to changes observed with BWS, the addition of a handrail hold increased single-limb support time in the paretic limb. Across the conditions of treadmill walking with handrail hold, harness support, and combined harness support and handrail hold, leg KE at toe-off in the nonparetic limb was reduced (-24\%) and swing time increased ( $+40 \%$ ) (Figure 2), which resulted in increased single-limb support time on the paretic limb [24]. Based on these findings, handrail hold appears to normalize multiple gait parameters during treadmill walking in hemiparetic individuals. Indeed, when less impaired individuals are being trained, handrail hold may be a reasonable alternative to harness support.

Other gait deviations observed in hemiparetic subjects included reduced peak knee flexion during swing and increased swing time in the paretic limb [26]. These deviations were not normalized with the adjustment of any of the locomotor training parameters considered in this review [24], which strongly suggests that manual assistance or other facilitatory approaches (e.g., functional electrical stimulation or robotic gait orthoses) are necessary augmentations to the treadmill and BWS parameters to address gait deviations associated with the swing phase of the paretic limb.

\section{DISCUSSION}

The immediate biomechanical effects of adjusting BWS, speed, support stiffness, and handrail hold during treadmill walking in hemiparetic and nondisabled subjects provide a basis for selection of locomotor training

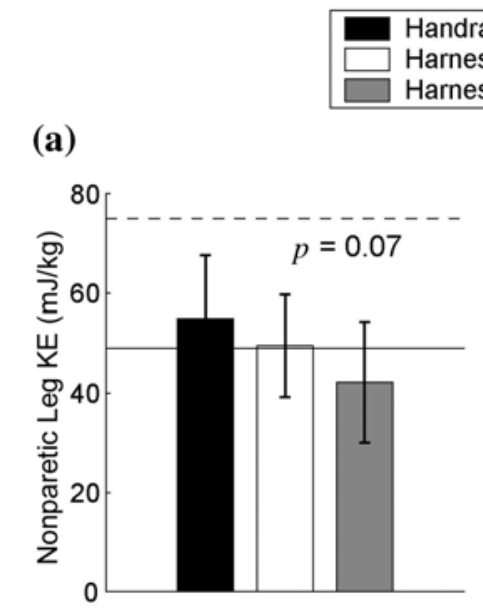

Handrail Hold

Harness Support

Harness + Handrail

(a)

(b)

\section{Figure 2.}

Differences between (a) leg kinetic energy at toe-off and (b) swing time for nonparetic limb with different types of support. Error bars represent standard error of mean. Dashed and solid lines represent, respectively, mean for hemiparetic and nondisabled control subjects during unsupported treadmill walking. Source: Chen G, Patten C, Kothari DH, Zajac FE. Gait deviations associated with post-stroke hemiparesis: Improvement during treadmill walking using weight support, speed, support stiffness, and handrail hold. Gait Posture. 2005;22(1):57-62. [PMID: 15996593]

parameters for persons with poststroke hemiparesis. Most of the reviewed studies advocated parameter settings that resulted in the normalization of temporal $[6-8,18,21-$ $22,24]$, kinematic $[6,22-24,29]$, kinetic $[8,23]$, or energetic gait deviations [24] during treadmill walking. Selection of such criteria is consistent with the clinical use of perceived improvements in gait patterns for guiding the adjustment of parameters during locomotor training and the facilitation of relevant task practice for promotion of skill acquisition [30-31]. It is argued that practice and reinforcement of a more normal gait pattern optimize the sensory inputs that are important in facilitating spinal and supraspinal locomotor networks [32] and maximizing the effectiveness of locomotor training. Moreover, walking with a more normal gait pattern, such as with increased single-limb support time, can increase the functional demands on the paretic limb, which may also contribute to positive treatment outcome $[7,18]$.

\section{Recommendations Based on Current Literature}

The current literature supports the use of adequate weight support (e.g., 35\%-50\%) during locomotor training in hemiparetic subjects. Both our investigations [24] and studies by Hesse et al. [6-7] found that single-limb 
support time in the paretic limb increased with BWS, which can contribute positively to treatment outcome. As a function of increased BWS, Hesse et al. also observed that hip and knee extension were increased during stance and hip and knee flexion were reduced during swing [6]. However, these findings were not replicated in our study, an outcome that may have occurred for two important methodological reasons [24]. First, the default stiffness of the harness support used in our study $(35.1 \mathrm{~N} / \mathrm{cm})$ [24] might have been less than the stiffness in the system used by Hesse et al. [6]. Stiffer BWS systems have been observed to lift subjects higher with increased support [21], which would reduce hip and knee flexion during walking. Second, the joint angles in our study [24] were assessed with a three-dimensional motion capture system, while the angles reported in Hesse et al. [6] were qualitatively assessed from monitor screens during videotape playback. Nevertheless, the significance of these kinematic changes at the hip and knee during walking [6], if they exist, is not clear. Increased hip and knee extension during stance can be regarded as a positive outcome. However, reduced hip and knee flexion during swing would not be desirable, since hemiparetic subjects exhibit reduced peak knee flexion during swing on their paretic side [26].

The current literature also supports the use of faster treadmill speeds that challenge the locomotor abilities of individuals with hemiparesis. With increased treadmill speed, we observed that leg KE at toe-off increased in the paretic limb [24]. This increase in leg energy at higher speeds was likely mediated by increased propulsion by the plantar flexors and/or hip flexors during preswing [33-35]. Consistent with this premise, Hesse et al. observed that electromyographic activities of gastrocnemius and other lower-limb muscles correlated positively with treadmill speed in hemiparetic subjects [22]. Also supporting the use of faster treadmill speeds, Hesse et al. observed that hemiparetic subjects exhibited greater metabolic efficiency while walking at faster treadmill speeds [22]. Moreover, both our personal investigations [24] and those of Hassid et al. [8] found that treadmill speed did not adversely affect symmetry in single-limb support time.

A biomechanical rationale exists for the use of a stiffer BWS system during training of individuals with hemiparesis. With increased support stiffness, we observed that the exaggerated energy cost associated with raising the trunk during preswing and swing of the paretic limb was reduced during treadmill walking [24] and, therefore, recommend the use of a stiffer support system during training of hemiparetic subjects. Similarly, Gordon et al. observed that a stiff BWS system reduced vertical movement of the pelvis in spinal-cord-injured and nondisabled subjects during treadmill walking [23]. However, their interpretations implied that a compliant support allowed for more natural displacements of the center of mass [23]. One study difference that may have resulted in our differing interpretations is that we compared our data with those of control subjects walking at slow speeds [24], where vertical trunk displacements are relatively small because of the subjects' short stride lengths, while Gordon et al. compared their data with control subjects who walked at fast speeds, where trunk displacements are larger [23]. Moreover, our study examined hemiparetic subjects and found their gaits to be characterized by exaggerated rises and falls in trunk height during the gait cycle [24]. Thus, a reduction in these exaggerated displacements normalized the overall motion profile of the trunk [24]. Further research is needed to determine whether a more compliant BWS system is warranted when hemiparetic subjects train at faster speeds, where, even in nondisabled subjects, trunk displacements are necessarily larger.

Our recent work supports the use of a handrail hold to normalize the gait pattern practiced by hemiparetic individuals during locomotor training [24]. We observed that the addition of handrail hold during harness-supported or unsupported treadmill walking increased single-limb support time in the paretic limb [24]. Previous studies on treadmill walking in persons with poststroke hemiparesis have neglected the potential effect of handrail hold [6-8,18,22]. Importantly, all the studies that reported improved gait symmetry and increased single-limb support time in the paretic limb during unsupported treadmill walking provided a handrail hold to the subjects [78,18 ]. Therefore, some, or all, of the positive gait changes observed in these studies may have been related to handrail hold and not treadmill walking per se. Moreover, since both handrail hold and BWS have similar effects in increasing single-limb support time of the paretic limb [24], treadmill training with handrail hold may be a reasonable alternative to training with harness support, especially in less impaired individuals.

\section{Unresolved Issues with Improving Paretic Limb Swing Phase Kinematics}

Augmentations to the treadmill and body support parameters appear to be necessary to address swing phase 
gait deviations in the paretic limb. In hemiparetic subjects who were able to advance their limbs independently, we observed that deviations in swing time and peak knee flexion during swing in the paretic limb were not normalized with the adjustment of BWS, speed, support stiffness, or handrail hold [24]. Thus, we recommend manual assistance or other facilitatory techniques to ensure proper kinematics of the paretic limb during swing. Manual assistance is commonly provided to hemiparetic individuals who cannot walk independently on the treadmill $[4-5,19]$, and its necessity greatly increases the physical demand on the therapists who apply the training. Several investigators are currently developing robotic gait orthoses to augment the locomotor training paradigm so that even severely impaired subjects can practice a gaitlike movement pattern [27,36-37]. Moreover, such devices promise to deliver more repeatable therapy and can provide additional kinematic and kinetic measurements during training to help guide the selection of parameters [36]. Further investigations are necessary to determine the biomechanical differences between locomotor training with and without robotic assistance.

\section{CONCLUSIONS}

As the rehabilitation potential of locomotor training is more extensively studied in hemiparetic individuals, a scientific basis for the proper selection of training parameters is needed. Currently, training protocols vary widely between experimenters and clinical settings. In a recent review that assessed the effectiveness of locomotor training in the treatment of walking after stroke [38], Moseley et al. found no statistical differences between locomotor training with or without BWS and other gait interventions for the clinical outcomes of walking speed or walking dependence [38]. However, their evaluation of the literature was based on a collection of studies that were markedly heterogeneous in terms of both clinical population and locomotor training prescription [38], which clearly affected their ability to consolidate and generalize the results. Before the effectiveness of locomotor training can be definitively evaluated, we must better understand the specific influences of the individual training parameters.

To initiate discussion between researchers and clinicians interested in the application of locomotor training for individuals with hemiparesis, we focused this review on the parameters of BWS, treadmill speed, support stiff- ness, and handrail hold, which exert important biomechanical effects on the gait pattern practiced by hemiparetic individuals. Other training parameters that merit systematic investigation include training frequency and duration and the use of manual assistance or robotic orthoses for guiding the movement pattern during the swing phase.

\section{ACKNOWLEDGMENTS}

This review is based, in part, on a doctor of philosophy dissertation by George Chen, Treadmill training with harness support: A biomechanical basis for selection of training parameters for individuals with post-stroke hemiparesis, Stanford University, Stanford, California, 2003. We thank Felix Zajac as the principal advisor.

This material was based on work supported by the Department of Veterans Affairs (VA) Rehabilitation Research and Development (RR\&D) Service (grant B2607P). George Chen was the recipient of a VA RR\&D Pre-Doctoral Fellowship and a Whitaker Foundation PreDoctoral Fellowship. Carolynn Patten is the recipient of VA RR\&D Career Development (grant D0701) and Advanced Career Development (grant D2206) Awards and a New Investigator Training and Fellowship Initiative from the Foundation for Physical Therapy, Alexandria, Virginia.

The authors have declared that no competing interests exist.

\section{REFERENCES}

1. Gresham GE, Duncan PW, Adams HP Jr, Adelman AM, Alexander DN, Bishop DS, Diller L, Donaldson NE, Granger CV, Holland AL, Kelly-Hayes M, McDowell FH, Myers LR, Phipps MA, Roth EJ, Siebens HC, Tarvin GA, Trombly CA. Post-stroke rehabilitation. Clinical practice guideline. No. 16. Rockville (MD): Agency for Healthcare Research and Quality, U.S. Department of Health and Human Services; 1995.

2. Jorgensen HS, Nakayama H, Raaschou HO, Olsen TS. Recovery of walking function in stroke patients: The Copenhagen Stroke Study. Arch Phys Med Rehabil. 1995; 76(1):27-32. [PMID: 7811170]

3. Hesse S, Bertelt C, Jahnke MT, Schaffrin A, Baake P, Malezic M, Mauritz KH. Treadmill training with partial body-weight support compared with physiotherapy in nonambulatory hemiparetic patients. Stroke. 1995;26(6):976-81. [PMID: 7762049] 
4. Sullivan KJ, Knowlton BJ, Dobkin BH. Step training with body-weight support: Effect of treadmill speed and practice paradigms on poststroke locomotor recovery. Arch Phys Med Rehabil. 2002;83(5):683-91. [PMID: 11994808]

5. Visintin M, Barbeau H, Korner-Bitensky N, Mayo NE. A new approach to retrain gait in stroke patients through body-weight support and treadmill stimulation. Stroke. 1998;29(6):1122-28. [PMID: 9626282]

6. Hesse S, Helm B, Krajnik J, Gregoric M, Mauritz KH. Treadmill training with partial body-weight support: Influence of body weight release on the gait of hemiparetic patients. J Neurol Rehabil. 1997;11(1):15-20.

7. Hesse S, Konrad M, Uhlenbrock D. Treadmill walking with partial body-weight support versus floor walking in hemiparetic subjects. Arch Phys Med Rehabil. 1999;80(4): 421-27. [PMID: 10206604]

8. Hassid E, Rose D, Commisarow J, Guttry M, Dobkin BH. Improved gait symmetry in hemiparetic stroke patients induced during body weight-supported treadmill stepping. J Neurol Rehabil. 1997;11(1):21-26.

9. Laufer Y, Dickstein R, Chefez Y, Marcovitz E. The effect of treadmill training on the ambulation of stroke survivors in the early stages of rehabilitation: A randomized study. J Rehabil Res Dev. 2001;38(1):69-78. [PMID: 11322472]

10. Pohl M, Mehrholz J, Ritschel C, Ruckriem S. Speeddependent treadmill training in ambulatory hemiparetic stroke patients: A randomized controlled trial. Stroke. 2002;33(2):553-58. [PMID: 11823669]

11. Da Cunha IT Jr, Lim PA, Qureshy H, Henson H, Monga T, Protas EJ. Gait outcomes after acute stroke rehabilitation with supported treadmill ambulation training: A randomized controlled pilot study. Arch Phys Med Rehabil. 2002; 83(9):1258-65. [PMID: 12235606]

12. Kosak MC, Reding MJ. Comparison of partial body weight-supported treadmill gait training versus aggressive bracing assisted walking post stroke. Neurorehabil Neural Repair. 2000;14(1):13-19. [PMID: 11228945]

13. Silver KH, Macko RF, Forrester LW, Goldberg AP, Smith GV. Effects of aerobic treadmill training on gait velocity, cadence, and gait symmetry in chronic hemiparetic stroke: A preliminary report. Neurorehabil Neural Repair. 2000; 14(1):65-71. [PMID: 11228951]

14. Werner C, Von Frankenberg S, Treig T, Konrad M, Hesse S. Treadmill training with partial body-weight support and an electromechanical gait trainer for restoration of gait in subacute stroke patients: A randomized crossover study. Stroke. 2002;33(12):2895-2901. [PMID: 12468788]

15. Nilsson L, Carlsson J, Danielsson A, Fugl-Meyer A, Hellstrom K, Kristensen L, Sjolund B, Sunnerhagen KS, Grimby G. Walking training of patients with hemiparesis at an early stage after stroke: A comparison of walking training on a treadmill with body-weight support and walking training on the ground. Clin Rehabil. 2001;15(5):515-27. [PMID: 11594641]

16. Daley K, Mayo N, Wood-Dauphinee S. Reliability of scores on the Stroke Rehabilitation Assessment of Movement (STREAM) measure. Phys Ther. 1999;79(1):8-19. [PMID: 9920188]

17. Berg KO, Wood-Dauphinee SL, Williams JI, Maki B. Measuring balance in the elderly: Validation of an instrument. Can J Public Health. 1992;83 Suppl 2:S7-11. [PMID: 1468055]

18. Harris-Love ML, Forrester LW, Macko RF, Silver KH, Smith GV. Hemiparetic gait parameters in overground versus treadmill walking. Neurorehabil Neural Repair. 2001; 15(2):105-12. [PMID: 11811252]

19. Hesse S. Treadmill training with partial body-weight support in hemiparetic patients-Further research needed. Neurorehabil Neural Repair. 1999;13(2):179-82.

20. Bayat R, Barbeau H, Lamontagne A. Speed and temporaldistance adaptations during treadmill and overground walking following stroke. Neurorehabil Neural Repair. 2005;19(2):115-24. [PMID: 15883355]

21. Finch L, Barbeau H, Arsenault B. Influence of body-weight support on normal human gait: Development of a gait retraining strategy. Phys Ther. 1991;71(11):842-55, discussion 855-56. [PMID: 1946621]

22. Hesse S, Werner C, Paul T, Bardeleben A, Chaler J. Influence of walking speed on lower limb muscle activity and energy consumption during treadmill walking of hemiparetic patients. Arch Phys Med Rehabil. 2001;82(11):1547-50. [PMID: 11689974]

23. Gordon KE, Ferris DP, Beres JA, Roberton M, Harkema SJ. The importance of using an appropriate body-weight support system in locomotor training. Soc Neurosci. 2000; 26(1):160.

24. Chen G, Patten C, Kothari DH, Zajac FE. Gait deviations associated with post-stroke hemiparesis: Improvement during treadmill walking using weight support, speed, support stiffness, and handrail hold. Gait Posture. 2005;22(1): 57-62. [PMID: 15996593]

25. Chen G, Schwandt D, Van der Loos HF, Anderson J, Ferris DP, Zajac FE, Kautz SA, Burgar CG, Patten C, Neptune RR, Gordon KE. Compliance-adjustable, force-sensing harness support for studying treadmill training in neurologically impaired subjects. In: Proceedings of the 6th Annual Gait and Clinical Movement Analysis Meeting; 2001 Apr 25-28; Sacramento (CA). Gait Posture. 2001;13:293-94.

26. Chen G, Patten C, Kothari DH, Zajac FE. Gait differences between individuals with post-stroke hemiparesis and nondisabled controls at matched speeds. Gait Posture. 2005; 22(1):51-56. [PMID: 15996592] 
27. Hesse S, Uhlenbrock D. A mechanized gait trainer for restoration of gait. J Rehabil Res Dev. 2000;37(6):701-8. [PMID: 11321006]

28. Olney SJ, Monga TN, Costigan PA. Mechanical energy of walking of stroke patients. Arch Phys Med Rehabil. 1986;67(2):92-98. [PMID: 3954572]

29. Barbeau H, Wainberg M, Finch L. Description and application of a system for locomotor rehabilitation. Med Biol Eng Comput. 1987;25(3):341-44. [PMID: 3449731]

30. Holding DH. Principles of training. New York (NY): Pergamon Press; 1965.

31. Newell KM. Skill learning. In: Holding DH, editor. Human skills. New York (NY): John Wiley and Sons, 1981. p. 203-26.

32. Dobkin BH. An overview of treadmill locomotor training with partial weight support: A neurophysiologically sound approach whose time has come for randomized clinical trials. Neurorehabil Neural Repair. 1999;13(3):157-65.

33. Nadeau S, Arsenault AB, Gravel D, Bourbonnais D. Analysis of the clinical factors determining natural and maximal gait speeds in adults with a stroke. Am J Phys Med Rehabil. 1999;78(2):123-30. [PMID: 10088586]

34. Nadeau S, Gravel D, Arsenault AB, Bourbonnais D. Plantarflexor weakness as a limiting factor of gait speed in stroke subjects and the compensating role of hip flexors. Clin Biomech. 1999;14(2):125-35. [PMID: 10619100]

35. Hof AL, Nauta J, Van der Knaap ER, Schallig MA, Struwe DP. Calf muscle work and segment energy changes in human treadmill walking. J Electromyogr Kinesiol. 1993; 2:203-16.

36. Colombo G, Joerg M, Schreier R, Dietz V. Treadmill training of paraplegic patients using a robotic orthosis. J Rehabil Res Dev. 2000;37(6):693-700. [PMID: 11321005]

37. Ferris DP, Czerniecki JM, Hannaford B. An ankle-foot orthosis powered by artificial muscles. In: Proceedings of 25th Annual Meeting of the American Society of Biomechanics; 2001 Aug 8-11; San Diego (CA). American Society of Biomechanics. 2001 Aug [cited 2005 Apr]. Available from: http://www.asbweb.org/

38. Moseley AM, Stark A, Cameron ID, Pollock A. Treadmill training and body-weight support for walking after stroke. Cochrane Database Syst Rev. 2003;(3):CD002840. [PMID: 12917932]

Submitted for publication April 5, 2005. Accepted in revised form January 10, 2006. 